\title{
Modeling on Disruption Risk Prediction of Manufacturing Supply Chain Based on C4.5 Algorithm
}

\author{
Weibin Wang ${ }^{1,2 *}$, Renyong $\mathrm{Chi}^{1}$, Caihong $\mathrm{Liu}^{2}$ \\ ${ }^{1}$ China Institute for Small and Medium Enterprises, Zhejiang University of Technology, Hangzhou \\ 310014, China \\ ${ }^{2}$ School of Business, Jiaxing University, Jiaxing 314001, China
}

Received: January 18, 2021. Revised: June 13, 2021. Accepted: July 8, 2021. Published: July 14, 2021.

\begin{abstract}
Under the impact of covid-19, the global and domestic manufacturing supply chains, almost suffered from the serious interruption crisis of manpower flow, logistics, information flow and capital flow. The risk of supply chain disruption has become the primary risk of the supply chain. However, some risk inducement of supply chain interruption is complex and diverse, so it is very difficult to grasp and screen the risk data needed for research from the supply chain operation data. To improve the robustness of supply chain for boosting the domestic and international circulation of China's manufacturing, in this paper, according to the characteristics of China's manufacturing supply chain and its risk incentives, the data needed for risk prediction modeling has been sorted out through questionnaire survey, and a regression model of risk prediction for manufacturing supply chain by using empirical method would be put forward. Then, C4.5 decision tree method is used to train and evaluation the risk prediction model. The conclusion shows that the customer satisfaction has great diagnostic value for risk, and the model has a strong sensitivity to market information risk and market order risk. The conclusion is more consistent with general cognition, and the model fits well, indicating that the model proposed in this paper has a certain theoretical significance, and its practical application value is worthy of further testing.
\end{abstract}

Keywords-Supply chain disruption; Risk prediction; Manufacturing; C4.5 algorithm.

\section{INTRODUCTION}

$\mathrm{F}$ OR a long time, China's manufacturing industry as a whole is at the middle and low end of the global manufacturing value chain. The added value of Chinese manufacturing is low, and production is deeply affected by the upstream and downstream of the chain. Thus, the supply chain (abbr.SC) of China's manufacturing is characterized by a long chain, intricate supply and demand links, and diverse nodes, which makes it vulnerable to the influence of uncertain factors inside and outside the SC. In short, the structure of China's manufacturing $\mathrm{SC}$ is more fragile than that of developed countries. The fluctuation of any node in the chain can spread rapidly and lead to unpredictable consequences. As a major manufacturer of intermediate products, China should strengthen the interruption risk management of its manufacturing supply chain, which is not only an issue related to China's economic development, but also a key aspect affecting global economic development. In recent years, SC disruption risk events caused by terrorist attacks, earthquakes, fires, ice disasters, economic crises, and etc have occurred from time to time, which have brought huge losses to node enterprises, SC management and society. Business managers and scholars have gradually paid attention to SC interruption risk management and countermeasures. Although there are many researches on supply chain risk management at present, the research on supply chain interruption risk prediction is relatively lagging, making it an important research topic that needs to be solved urgently [1]. Especially, under the impact of the covid-19, the fluctuations in customer demand that need to be digitally addressed [2], the importance of supply and demand stability of China's manufacturing industry has attracted considerable attention. At the beginning of the difficulties, China's manufacturing also suffered from serious material shortage, poor logistics, lack of human resources, imbalance between supply and demand and other problems. The Chinese government timely put forward the strategy of building a new development pattern of mutual promotion at home and abroad, realizing the upgrading of industrial foundation and the modernization of industrial chain, and rapidly improving the stability and competitiveness of industrial chain and SC [3]. However, the close relationship between supply and demand at home and abroad makes the main body of supply chain more 
involved, and the structure of supply chain tends to be larger and more complex. Therefore, the supply network system is more vulnerable to external and internal interference.

At present, there are still few studies on SC interruptions in manufacturing industry. For example, some studies on SC interruptions review $[4,5]$ basically do not distinguish interruptions in different industries. There is a lack of thinking about some SC interruption problems according to the characteristics of manufacturing SC. At the same time, the connotation closely related to SC interruption includes the robustness of SC, the flexibility of SC, the vulnerability of SC, etc., so in the analysis of SC interruption risk, the extraction of risk factors is not uniform.

To this end, this paper should analyze the SC interruption risk factors based on the characteristics of the manufacturing supply chain, and carry out risk prediction modeling and simulation.

\section{LITERATURE REVIEW}

According to the research idea of this paper, based on the understanding of the concept of supply chain disruption risk, this paper will review the research on the influencing factors, risk identification and risk management of SC disruption risk.

\section{A. Definition of Disruption Risk in SC}

$\mathrm{SC}$ interruption risk refers to various uncertainties existing in the operation of supply chain, which are gradually developed on the basis of SC risks [6]. Guo et al. [7] believe that SC disruption is caused by internal and external risk factors of the SC, which is manifested in the sudden occurrence of accidents that make the supply volume and customer demand, quality or cost deviate significantly from the originally scheduled SC management objectives. Li et al. [8] hold that both external environmental factors (such as natural disasters, emergencies, policy changes, epidemic viruses, political and social opinions, etc.) and internal factors (such as zero inventory management) of the supply chain will increase the risk of supply chain interruption. According to Cranfield (2002), interruption risk is an inherent characteristic of SC risk, which is caused by various uncertain factors. Symbiosis between SC enterprises magnifies the risk [9]. Chopra and Sodhi [10] think that different disruption risk in SC will affect each other, so the importance of risk and input-output ratio should be weighed in risk management.

There is no unified understanding on the interruption risk of SC. Scholars at home and abroad have defined it from different perspectives, but the general content is consistent, that is, it is the potential harm that some internal and external risk inducers may bring about the instability of SC relationship structure.

\section{B. Risk Factors of Supply Chain Disruption}

Tang [11] proposed that there are mainly two kinds of SC risks, one is the operational risk caused by improper operation of the supply chain, the other is the interruption risk caused by the external environment, such as terrorist attacks, natural disasters and epidemics. Sodhi and Tang [12] thinks that SC risk mainly includes three levels: application level, intra organization and inter organization, among which application level risk includes interruption risk. Cavinato [13] recognizes that SC interruption risks come from logistics, capital flow, information flow, network and innovation network. The Supply on the supply side is prone to disruptions, and precautionary investments should be made in supply facilities and each customer should be assigned both a primary supplier and an alternative supplier [14]. Jalali et al. [15] assumed that the distribution center was vulnerable to interruption risks and established a mixed integer programming model aiming at minimizing cost and maximizing fill rate.

Most studies pay more attention to the external risk factors of $\mathrm{SC}$ interruption, and, and less on the internal risk factors within the chain. This is also the focus of this paper.

\section{The Identification and Management of Interruption Risk} in $S C$

Ellis et al. [16] found that the risk of supply disruption is the key risk that must be identified. Wu et al. [17] constructed a hierarchical supply risk classification and evaluation model by using factor analysis. Schoenherr et al. [18] identified 17 risk factors of SC disruption based on behavioral risk theory and analytic hierarchy process. Shu et al. [19] built a SC risk assessment model based on support vector machine. Xiao et al. [20] established a SC risk assessment model based on fuzzy theory to calculate the probability, loss and consequences of risk. $\mathrm{Yu}$ and $\mathrm{Wu}[21]$ studied the value and impact of business interruption insurance by establishing a single-cycle SC interruption model. Ledari puts forward that the main factors affecting the interruption risk of order quantity and profit include the probability of interruption and the percentage of order quantity satisfied when interruption occurs [22]. Fan [23] models and simulates SC interruption risks from the perspectives of stability, interruption recovery time, demand amplification and frequency response based on control theory. Zhang et al. [24] established the emergency strategy model of supply disruption risk by using system dynamics. Schmitt $e t$ al [25] found that dynamic ordering strategies can help the SC better respond to interruptions through simulation and multi-objective functions. Jiang et al. put forward a comprehensive evaluation model based on fuzzy comprehensive evaluation and artificial neural network method. The actual data test shows that compared with other methods, the evaluation accuracy is higher and the method is simple and easy to operate [26].

\section{The commentary}

On the whole, there are more studies on the interruption risk of a single node in SC, and fewer studies on the interruption risk management in the entire $\mathrm{SC}$; there are more studies on the interruption risk under normal conditions of SC, and fewer studies under the dynamic abnormal conditions. Moreover, the research on the prediction and control of the interruption risk of the manufacturing $\mathrm{SC}$ is relatively lacking. 


\section{ANALYSIS OF THE INTERRUPTION RISK OF MANUFACTURING SUPPLY CHAIN BASED ON UNCERTAIN DEMAND THEORY}

In the modern manufacturing, consumers' uncertain demands are intensified, and the relationship between supply and demand is closer. The manufacturing SC is no longer a simple structure of production supply, but gradually becomes serviced. The uncertainty of supply and demand also increases. Regarding this, the occurrence probability of manufacturing SC interruption risk is also gradually increasing.

\section{A. The Mechanism of Disruption Risk in Manufacturing SC} Under Uncertain Demand Conditions

With the further integration of various advanced information technologies in SC management, each node in the SC is faced with the uncertainty of demand information. The demand uncertainty faced by SC members can be roughly divided into two types: one is the asymmetric information distribution of SC members, which leads to the lack of real and effective demand information within the SC system; the other is the incomplete demand information received by SC members, which leads to the lack of demand information outside the SC system necessary for making correct decisions [27]. Zhang et al. [28] studied the robust control problem of SC network with lead time under internal and external uncertainties such as production capacity, SC structure and customer demand. From the perspective of bullwhip effect, Lu et al. [29] believed that SC information sharing could enable manufacturing enterprises to predict the demand of upstream enterprises more accurately and enable manufacturers to reduce the fluctuation of enterprise inventory. When enterprises in the SC share information, they will take into account the security of their own information resources, and excessive sharing should not allow competitive enterprises to obtain business information [30], which makes it difficult to determine the demand information and predict the market demand accurately. Zhou and Ma [31] presented the information sharing game equilibrium model of the two-tier SC system of manufactor-retailer based on the uncertain demand environment. Wilson [32] studied the action mechanism of transportation interruption risk based on system dynamics, and pointed out that transportation interruption had the greatest impact on upstream suppliers. Wierczek [33] compares the physical flow and information flow in SC to snowball, and thinks that the process of interruption risk passing along the SC is actually the snowball of real logistics and information flow. The research finds that the transmission strength of interruption risk can be weakened by increasing the integration dimension.

In summary, under the uncertain demand information, the risk of interruption in the manufacturing SC comes from the uncertainty of market demand, the uncertain supply, and the uncertainty of the relationship in SC.

\section{B. The Disruption Risk Classification of Manufacturing SC Under Uncertain Demand Conditions}

With the shortening of the production cycle of products, the diversified and personalized needs of customers, and the enlarged space for the optimal allocation of supply and demand resources, the uncertainty of the market is gradually increasing. Based on demand fluctuations, this paper summarizes the hierarchical structure [34] of the sources and factors of SC interruption risk, as shown in Fig. 1.

From the perspective of demand, the failure mode of SC is mainly oversupply and short supply. The causes of SC failure are that the company's poor grasp and utilization of market information leads to the inability to grasp market demand in time, the supplier's own ability to meet the demand [31], and the structure vulnerability of the SC caused by the sudden broken chains, and other risks.

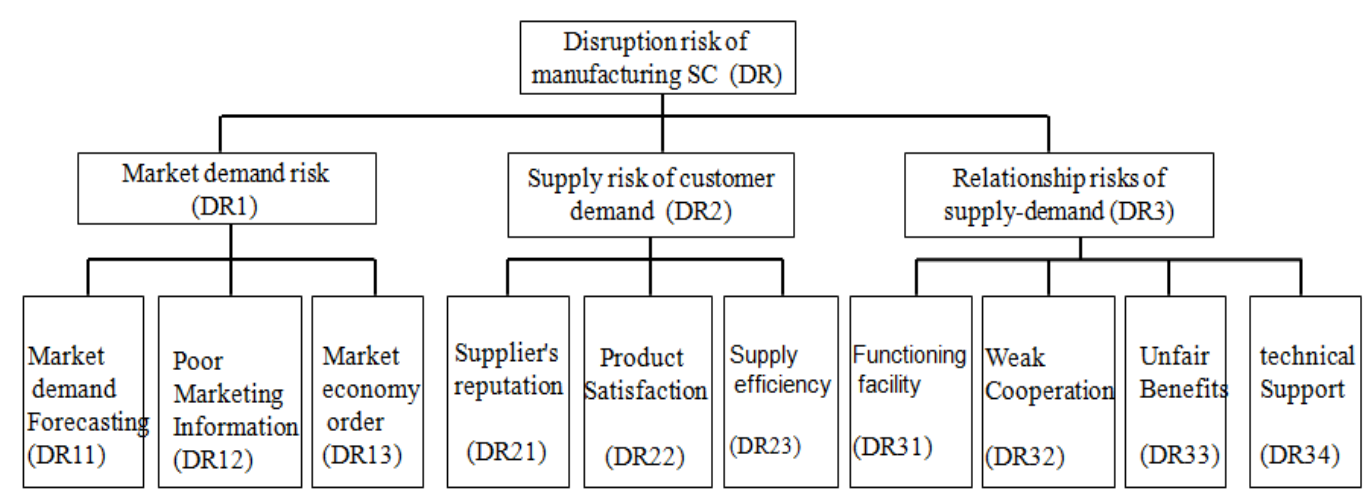

Fig. 1 The composition of disruption risk of manufacturing SC

\section{EMPIRICAL DATA ANALYSIS}

According to the question dimensions in Figure 1, the survey questionnaire items were designed and selected, and some manufacturing companies in China were selected for telephone survey. Finally, 138 valid questionnaires were obtained out of 155 questionnaires. Use SPSS22 stupid software to make a preliminary analysis of the data.

\section{A. The Reliability and Validity of the Questionnaire}

The Cronbach $\alpha$ coefficient of the questionnaire data is 0.74 , ranging from 0.7 to 0.8 , which indicates that the reliability of the data is high and can be used for further analysis. Meanwhile, the validity analysis is shown in Table 1 . 
Table 1 suggests that the KMO value is 0.732 , between 0.7 and 0.8 , denoting good validity of the research data. In addition, the cumulative variance interpretation rate of the three factors after rotation was $67.242 \%>50 \%$. It means that the information of research items can be extracted effectively. Finally, according to the factor loading coefficient, it can be known that the corresponding relationship between the factor (dimension) and the research item is in line with the expectation, indicating that the composition of risk factors is reasonable.

Table 1 The validity analysis

\begin{tabular}{|c|c|c|c|c|}
\hline \multirow{2}{*}{ Item } & \multicolumn{3}{|c|}{ Factor loadings } & \multirow{2}{*}{ variance of common factor } \\
\hline & Factor 1 & Factor 2 & Factor 3 & \\
\hline DR11 & 0.192 & 0.01 & 0.7 & 0.527 \\
\hline DR12 & 0.051 & -0.022 & 0.847 & 0.721 \\
\hline DR13 & -0.003 & 0.246 & 0.837 & 0.761 \\
\hline DR21 & -0.021 & 0.862 & 0.055 & 0.747 \\
\hline DR22 & 0.171 & 0.868 & 0.01 & 0.783 \\
\hline DR23 & 0.108 & 0.852 & 0.138 & 0.756 \\
\hline DR31 & 0.697 & 0.074 & 0.14 & 0.51 \\
\hline DR32 & 0.821 & 0.065 & 0.066 & 0.683 \\
\hline DR33 & 0.818 & 0.048 & -0.017 & 0.672 \\
\hline DR34 & 0.741 & 0.079 & 0.098 & 0.565 \\
\hline Eigenroot value (before rotation) & 3.087 & 1.955 & 1.682 & - \\
\hline Cumulative variance interpretation rate $\%$ (before rotation) & $30.869 \%$ & $50.417 \%$ & $67.242 \%$ & - \\
\hline Cumulative variance interpretation rate $\%$ (after rotation) & $24.587 \%$ & $47.607 \%$ & $67.242 \%$ & - \\
\hline KMO & \multicolumn{3}{|c|}{0.732} & - \\
\hline Bartlett'test & \multicolumn{3}{|c|}{444.386} & \\
\hline $\mathrm{df}$ & \multicolumn{3}{|c|}{45} & \\
\hline $\mathrm{p}$ & \multicolumn{3}{|c|}{0} & \\
\hline
\end{tabular}

\section{B. The Discriminant Validity Analysis of Items}

In order to further test the usability of the questionnaire research items, after summing the 10 data items, they were divided into high and low groups, and t-test was used to compare the differences shown as Table 2.

Table 2 The discriminant validity

\begin{tabular}{|c|c|c|c|c|}
\hline & \multicolumn{2}{|c|}{ Group (mean \pm SD) } & \multirow{2}{*}{$\mathrm{T}$} & $\mathrm{P}$ \\
\cline { 2 - 3 } & Low group $(\mathrm{n}=44)$ & High group $(\mathrm{n}=38)$ & & \\
\hline DR11 & $3.61 \pm 0.92$ & $4.61 \pm 0.64$ & -5.727 & $0.000 * *$ \\
\hline DR12 & $3.43 \pm 1.25$ & $4.74 \pm 0.50$ & -6.37 & $0.000 * *$ \\
\hline DR13 & $2.27 \pm 1.09$ & $4.13 \pm 0.81$ & -8.849 & $0.000 * *$ \\
\hline DR21 & $3.57 \pm 1.07$ & $4.50 \pm 0.60$ & -4.953 & $0.000 * *$ \\
\hline DR22 & $2.27 \pm 1.09$ & $4.00 \pm 0.90$ & -7.872 & $0.000 * *$ \\
\hline DR23 & $3.68 \pm 0.88$ & $4.79 \pm 0.41$ & -7.43 & $0.000 * *$ \\
\hline DR31 & $3.36 \pm 1.06$ & $4.68 \pm 0.47$ & -7.464 & $0.000 * *$ \\
\hline DR32 & $3.55 \pm 0.98$ & $4.74 \pm 0.45$ & -7.269 & $0.000^{* *}$ \\
\hline DR33 & $3.77 \pm 0.94$ & $4.74 \pm 0.45$ & -6.076 & $0.000^{* *}$ \\
\hline DR34 & $3.82 \pm 0.99$ & $4.71 \pm 0.52$ & -5.198 & $0.000^{* *}$ \\
\hline \multicolumn{4}{|c|}{$* \mathrm{P}<.0 .5 * * \mathrm{P}<0.01$} \\
\hline
\end{tabular}

As we can see that the differences of DR11, DR12, DR13, DR21, DR22, DR23, DR31, DR32, DR33 and DR34 are significant from the high and low groups $(\mathrm{P}<0.05)$, indicating that all 10 items were well differentiated and there was no need to delete the analysis item.

\section{Modeling OF DisRUPtion Risk PREDICTION IN} Manufacturing Supply Chain BaSed on DeCision TREe

\section{A. The Decision Tree Method Based on C4.5 Algorithm}

Decision tree method, as one of the main methods of prediction modeling, has been widely used in many fields. There are three basic algorithms for decision tree. Among them, CLS algorithm has great randomness in attribute selection and low prediction efficiency. In contrast, ID3 algorithm can select nodes according to the information gain value of attributes, but it has too much emphasis on attributes with more branches. C4.5 algorithm with information increase rate can avoid some disadvantages of the above two methods, and it has high precision and efficiency for decision tree modeling of small sample data and continuous sample data $[35,36]$. At the same time, although other predictive modeling methods can be used, such as Neural Network Modeling method, but the model based on Neural Network often needs to set the level of neural network and the number of neurons in each layer, and the utility of the model established by different levels and numbers will be different. Sometimes it takes more time and complex calculation to build a proper model. However, the C4.5 algorithm selects the branch of the model through the information gain value, so the model will be simpler and more comprehensive. Therefore, this paper will apply C4.5 algorithm to risk modeling.

Assume that a decision information table is composed of $M$ enterprises, $N$ enterprise attributes $(C)$ and one decision attribute $(D)$. Each attribute is set to $K$ values. The $\mathrm{C} 4.5$ decision tree model can be expressed as: 


$$
f\left(C_{i}\right)=\left(I(D)-I\left(C_{i}\right)\right) / H\left(C_{i}\right)
$$

where, $N \ni i . I(D)$ represents the information entropy of the decision attribute. $I\left(C_{i}\right)$ is the information entropy of the $\mathrm{i}$-th conditional attribute. $H\left(C_{i}\right)$ is the split value of the $\mathrm{i}$-th conditional attribute.

$$
I\left(C_{i}\right)=\sum_{j=1}^{N}\left(I\left(C_{i j}\right) *\left(\sum_{k=1}^{K} C_{i j} / M\right)\right)
$$

where, $\sum C_{i j}$ is the number of the $\mathrm{j}$-th attribute value of the $\mathrm{i}$-th conditional attribute.

\section{B. Decision tree modeling for risk prediction}

The C4.5 decision tree algorithm based on part of the empirical data in this paper is realized by WEKA3.8 software. By adjusting the pre-pruning parameters of the decision tree, and when the sample number range of branches is $2-4$, the maximum continuous branch range of node is $2-3$, the depth range of tree is $4-5$, and the error rate is less than $30 \%$, the model will be stable. Therefore, the prediction model constructed in this paper is shown as Fig. 2.

The decision rules of risk prediction are shown in Fig. 2, in which there are 7 prediction paths with confidence level greater than or equal to $50 \%$. As can be seen from Fig. 3, the importance of each risk index is given in Table 3 .

Obviously, DR2 is the most important SC interruption risk factor. This also verifies the importance of the company's customer-centric management philosophy. Although DR3 is less important than the other two risk factors, it cannot be ignored, especially the technical guarantee of DR34 to the formation and stability of SC. Concurrently, except for DR32, which was pruned off from the forming of a decision tree, other indicators have played a certain role.

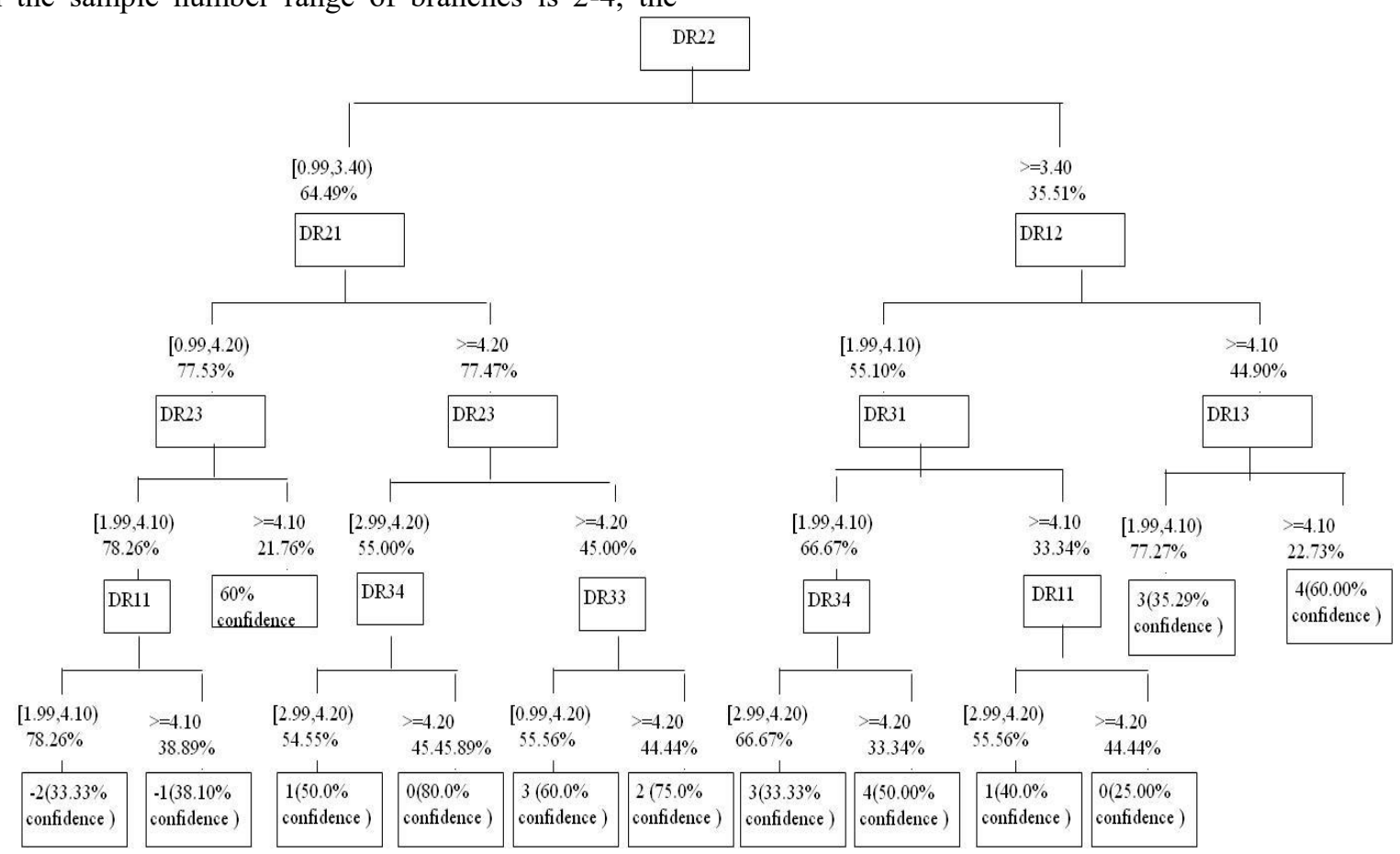

Fig. 2 The prediction model of manufacturing supply chain

Table 3 The importance of risk predictors

\begin{tabular}{|c|c|}
\hline Index & Sig. \\
\hline DR22 & 100 \\
\hline DR21 & 84.749 \\
\hline DR23 & 76.088 \\
\hline DR11 & 17.0211 \\
\hline DR13 & 15.016 \\
\hline DR12 & 14.9568 \\
\hline DR34 & 11.0872 \\
\hline DR33 & 9.2118 \\
\hline DR32 & 8.0343 \\
\hline DR31 & 7.9985 \\
\hline
\end{tabular}

\section{The Model Evaluation}

According to the given prediction model and the actual value of the SC disruption risk of manufacturing enterprises, based on the reserved 15 data sets, the SC disruption risk of enterprises should be predicted. The fitting between the prediction result and the actual risk value is shown in Fig. 3. 


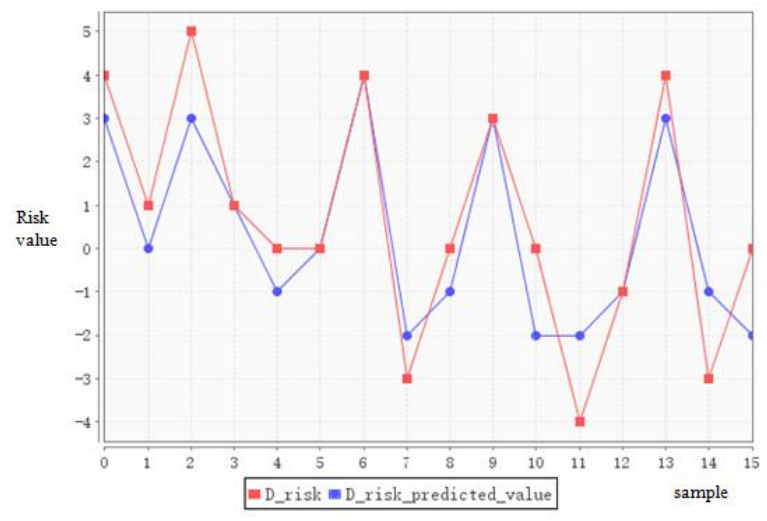

Fig. 3 Model fitting

This figure reveals that there is a good fit between the actual risk value and the predicted risk value. Therefore, it can be seen that the SC disruption risk prediction model proposed in this paper has a certain practical application value.

\section{Discussion}

Through figure 2 , we can not only see the composition of SC disruption risk factors in manufacturing industry, but also see the transmission mechanism of SC disruption risk. First, in terms of risk dimension, the risk of customer demand is greater than the risk of enterprise's response to the market. Compared with the former two, the structural risk of SC itself is the least important. This shows that the root risk of SC disruption lies in the customer satisfaction with the supply services provided by the enterprise. This in turn depends on the timely grasp of market fluctuation information and the decision-making ability of dynamic response for an enterprise. Furthermore, the enterprise's ability to respond to the market depends on the supply chain structure and the informationization of the SC structure. Then, although the harmfulness of the three risk dimensions is different, the three risk dimensions are interrelated, and the risks are transmitted to each other, and the risk hazards are gradually increasing. Therefore, in view of the $\mathrm{SC}$ interruption risk that is often faced in the manufacturing industry, enterprises should take comprehensive risk pre-control measures in advance, and should not only pay attention to the SC risk in a certain link. Similarly, in terms of countermeasures, enterprises should optimize their SC management mode, expand the open cooperation strategy of the $\mathrm{SC}$, increase the cooperation nodes in SC and increase the horizontal cooperation chains among SC under the management concept of "customer-centered". In order to improve the real-time monitoring and management of SC risk information, the traditional operation mode of $\mathrm{SC}$ should be gradually changed to digital operation mode.

\section{CONCLUSION}

With the continuous development of advanced manufacturing models, the manufacturing SC has become more and more complex. The manufacturing companies are increasingly facing more and more complex disruption risks of SC. In order to prevent such risks and promote the healthy development of China's manufacturing industry, this paper proposes a prediction model for the interruption risk of the manufacturing SC. Because the sub indicators of the three dimensions of DR1, DR2 and DR3 have constitute the risk prediction decision tree shown in Figure 2, and the decision tree model is well fitted after simulation training. This shows that the three risk dimensions in the model can explain the chain breakage risk of manufacturing SC. Customer demand satisfaction is the most important factor affecting the stability of SC. Enterprises should pay attention to product quality and service quality to improve customer stickiness. The quality of supply to meet the customer's demand indirectly affects the quality of products, and the quality of supply is often directly related to the reputation of suppliers. Therefore, the reputation of supply is also the key to the broken chain risk. In addition to the ability of market demand prediction and market information acquisition, market order should also be the important factors of chain breaking risk.

In addition, in practice, in addition, the prediction model proposed in this paper has the stability and reliable prediction ability through simulation fitting. This can be applied to the SC interruption risk prediction effectively, and can also provide scientific guidance for the production, inventory management and demand forecast of manufacturing SC.

On the whole, this research is helpful to prevent the risk of "broken chain" in China's manufacturing industry due to material shortage and "reverse globalization".

\section{ACKNOWLEDGMENT}

This research was supported by the Social Science Planning Project of Zhejiang Province (Grant No. 17NDJC093YB), Zhejiang Soft Science Project (Grant No. 2019C25012) and the Natural Science Foundation of Zhejiang Province in China (Grant No. LY18G010011).

\section{REFERENCES}

[1] C. X. Liu, "Research on Supply Chain Interruption Risk Transmission Mechanism and Interruption Risk Prediction", Doctoral Dissertation of Hunan University, 2016.

[2] K. M. Alomari, "Digital Marketing During COVID 19: Consumer's Perspective", WSEAS Transactions on Business and Economics, vol. 17, pp. 831-841, 2020.

[3] Z. C. Xie, "Improving the Stability and Competitiveness of Industrial Chain Supply Chain", Truths and Facts, no. 9, pp. 7-9, 2020.

[4] H. P. Mu, "Disruption management of flexible job shop scheduling considering behavior perception and machine fault based on improved NSGA-II algorithm", Journal Européen des Systèmes Automatisés, vol. 52, no. 2, pp. 149-156, 2019. https://doi.org/10.18280/jesa.520206

[5] H. Song and X. Y. Yang, "A Literature Review on Supply Chain Risk Management", Supply Chain Management, vol. 1, no. 3, pp. 33-45, 2020. 
[6] F. Yang, "Research on Supply Chain Disruption Risk Influence and Dual-source Coordination Optimization", Master Dissertation of Hunan University, 2015.

[7] X. Guo et al., "Review of Research on Managing Disruption Risks in Supply Chains", China Business and Market, vol. 25, no. 3, pp. 48-53, 2011. https://doi.org/10.3969/j.issn.1007-8266.2011.03.011

[8] B. Li et al., "Research on Supply Chain Management Based on Reducing Supply Interruption Risk", Modern Management Science, no. 9, pp. 5-7, 2011. https://doi.org/10.3969/j.issn.1007-368X.2011.09.002

[9] Y. Wang and J. F. Chen, "Supply Chain Event Management: from Technology to Methodology", Forecasting, vol. 23, no. 1, pp. 62-65, 2004. https://doi.org/10.3969/j.issn.1003-5192.2004.01.014

[10] S. Chopra and M. M. S. Sodhi, "Managing Risk To Avoid Supply-Chain Breakdown", MIT Sloan Management Review, vol. 46, no. 1, pp. 53-61, 2004.

[11]C. S. Tang, "Perspectives in Supply Chain Risk Management", Social Science Electronic Publishing, vol. 103, no. 2, pp. 451-488, 2006. https://doi.org/10.2139/ssrn.925274

[12]M. M. S. Sodhi and C. S. Tang, "Supply Chain Risk Management", Wiley Encyclopedia of Operations Research and Management Science, John Wiley \& Sons, Inc. 2011.

[13] J. L. Cavinato, "Supply Chain Logistics Risks: From the Back Room to the Board Room", International Journal of Physical Distribution \& Logistics Management, vol. 34, no. $5, \quad$ pp. $383-387, \quad 2004$. https://doi.org/10.1108/09600030410545427

[14] T. Cui et al., "Reliable Facility Location Design Under the Risk of Disruptions", Operations Research, vol. 58, no. 4, pp. iii-1033, 2010. https://doi.org/10.1287/opre.1090.0801

[15] S. Jalali et al., "Optimizing a Bi-objective Reliable Facility Location Problem with Adapted Stochastic Measures Using Tuned Parameter Multi-Objective Algorithms", Knowledge-Based Systems, vol. 95, no. 1, pp. 45-57, 2016. https://doi.org/10.1016/j.knosys.2015.12.001

[16] S. C. Ellis et al., "Buyer Perceptions of Supply Disruption Risk: A Behavioral View and Empirical Assessment", Journal of Operations Management, vol. 28, no. 1, pp. 34-46, 2010. https://doi.org/10.1016/j.jom.2009.07.002

[17]B. Wu, "Research and Application of Performance Prediction Model Based on Decision Tree Algorithm", Shaanxi: Master's thesis of Xi'an University of technology, 2019.

[18] T. Schoenherr et al., "Assessing Supply Chain Risks with the Analytic Hierarchy Process: Providing Decision Support for the Offshoring Decision by a US Manufacturing Company", Journal of Purchasing \& Supply Management, vol. 14, no. 2, pp. 100-111, 2008. https://doi.org/10.1016/j.jom.2009.07.002

[19] T. Shu et al. "Research on Supply Chain Risk Assessment Based on Support Vector Machine", Economic Survey, vol. 31, no. 1, pp. 130-135, 2014. https://doi.org/CNKI:SUN:JJJW.0.2014-01-025
[20] M. D. Xiao et al., "Assessment of Supply Chain Risk Based on Uncertainty Theory and Fuzzy Method", Soft Science, vol. 21, no. 5, pp. 27-30, 2007. https://doi.org/10.3969/j.issn.1001-8409.2007.05.007

[21] H. Yu and T. F. Wu, "An Analysis of Supply Chain Disruption Modal based on Business Interruption Insurance", Insurance Studies, no. 5, pp. 24-35, 2016. https://doi.org/10.13497/j.cnki.is.2016.05.003

[22] A. M. Ledari et al., "A New Newsvendor Policy Model for Dual-sourcing Supply Chains by Considering Disruption Risk and Special Order", Journal of Intelligent Manufacturing, vol. 29, no. 1, pp. 237-244. https://doi.org/10.1007/s10845-015-1104-y

[23] W. Fan, "Information Management Strategies and Supply Chain Performance Under Demand Disruptions", International Journal of Production Research, vol. 54, no. 1, pp. 1-20, 2016.

[24]Y. B. Zhang et al., "Contingency Police and Operation Simulation of Supply Chain Disruption with Changing Demand", Journal of Systems \& Management, vol. 28, no. 6, pp. 1202-1210, 2019. https://doi.org/10.3969/j.issn.1005-2542.2019.06.022

[25]T. G. Schmitt et al., "Mitigating Disruptions in a Multi-echelon Supply Chain Using Adaptive Ordering", Omega, vol. 68, pp. 185-198, 2017. https://doi.org/10.1016/j.omega.2016.07.004

[26] Y. L. Jiang et al., "ANN-based Comprehensive Evaluation Model of Supply Chain Risk and Its Application", Journal of Wuhan University of Technology (Transportation Science and Engineering), vol. 32, no. 1, pp. 70-73, 2008. https://doi.org/10.3963/j.issn.2095-3844.2008.01.019

[27]C. Wang, L. Zeng, "Optimization of multi-objective job-shop scheduling under uncertain environment", Journal Européen des Systèmes Automatisés, vol. 52, no. 2, pp. 179-183, 2019. https://doi.org/10.18280/jesa.520210

[28] S. T. Zhang et al., "Robust Control of Uncertain Supply Chain Network With Lead Times", Computer Integrated Manufacturing Systems, vol. 21, no. 1, pp. 266-279, 2015. https://doi.org/10.13196/j.cims.2015.01.029

[29] J. Z. Lu et al., "Factors Affecting Bullwhip Effect of Inventory Under Information Sharing", Journal of Management Sciences in China, vol. 20, no. 3, pp. 136-147, 2017. https://doi.org/10.3969/j.issn.1007-9807.2017.03.010

[30] Y. Chen et al., "Research of Information Sharing and Cooperative Innovation in Industrial Cluster", Systems Engineering Theory \& Practice, vol. 24, no. 8, pp. 54-57, 2004. https://doi.org/10.3321/j.issn :1000-6788.2004.08.009

[31]X. W. Zhou and F. C. Ma, "An Incentive Model of Information Sharing in Supply Chain with Demand Uncertainty", Journal of Industrial Engineering and Engineering Management, vol. 24, no. 4, pp. 122-126, 121, 2010.

https://doi.org/10.3969/j.issn.1004-6062.2010.04.019

[32] M. C. Wilson, "The Impact of Transportation Disruptions on Supply Chain Performance", Transportation Research Part E Logistics \& Transportation Review, vol. 43, no. 4, pp. 295-320, 2007. https://doi.org/10.1016/j.tre.2005.09.008 
[33] A. Swierczek, "The Impact of Supply Chain Integration on the "Snowball Effect" in the Transmission of Disruptions: An Empirical Evaluation of the Model", International Journal of Production Economics, vol. 157, pp. 89-104, 2014. https://doi.org/10.1016/j.ijpe.2013.08.010

[34]C. Bensaci, Y. Zennir and D. Pomorski, "A Comparative Study of STPA Hierarchical Structures in Risk Analysis: The Case of a Complex Multi-Robot Mobile System", WSEAS Transactions on Computers, vol. 18, no. 22, pp. 163-174, 2019.

[35] S. Sikder, S. K. Metya, R. S. Goswami, "Exception-tolerant decision tree / rule based classifiers", Ingénierie des Systèmes d'Information, vol. 24, no. 5, pp. 553-558, 2019. https://doi.org/10.18280/isi.240514

[36] M. Li, "A Study on the Influence of Non-intelligence Factors on College Students' English Learning Achievement Based on C4.5 Algorithm of Decision Tree", Wireless Personal Communications, vol. 102, pp. 1213-1222,

2018.

https://doi.org/10.1007/s11277-017-5177-0

Weibin Wang, since 2015, is a $\mathrm{PhD}$ candidate in China institute for small and medium enterprise, Zhejiang University of Technology, China; and a full Assistant Professor of College of business, Jiaxing University, China.

Since 2012, he has been an Associate Professor with Jiaxing University. His research interests include SME management and supply chain management.

Renyong Chi received the Ph.D. degree from China Agricultural University, Beijing, China, in 2005. From 1999 to 2000, he was a visiting scholar in the Business Department of Hitotsubashi University, Japan.

Since 2002, he has been a Professor of China institute for small and medium enterprise, Zhejiang University of Technology. His researcher activity is in the area of SME innovation management, SME entrepreneurial environment, and SME development and policy.

Caihong Liu received the Ph.D. degree from University of Shanghai for Science and Technology, Shanghai, China, in 2009 .

From 2012 to 2015, she was a postdoctoral fellow at Zhejiang University. Since 2013, she has been an associate professor of Business School, Jiaxing University, China. Heir researcher activity is in the area of supply chain risk management, and information intelligent decision.

\section{Creative Commons Attribution License 4.0 (Attribution 4.0 International, CC BY 4.0)}

This article is published under the terms of the Creative Commons Attribution License 4.0

https://creativecommons.org/licenses/by/4.0/deed.en_US 